\title{
Management of Pig Cages in Baru Village, Marga Sub- district, Tabanan Regency
}

\author{
I Gusti Ayu Dewi Seri Rejeki ${ }^{1}$, Ni Ketut Mardewi ${ }^{2}$, and Ni Ketut Sri Rukmini ${ }^{3}$ \\ \{igadrejeki@gmail.com\} \\ Warmadewa University
}

\begin{abstract}
The pig farmer group located in Baru Village, Marga Sub-district, Tabanan Regency, has been raising pigs since 2014. However, this group always experiences problems associated with pig cage management such as low weights and high mortality rates. Therefore, the right cage sanitation settings need to be applied when raising pigs to achieve tremendous success. The method used in implementing this training are face-to-face interviews, counseling and direct practice. The activities were carried out in stages. Firstly, general counseling on proper pig management were carried out to specifically explain how cages and mortality rates are managed. This is because the optimal weight of the 102 pigs used in this study failed to reach $15 \%$ with mortality rates below the normal percentage of $11-24 \%$. Secondly, direct practice were carried out in the cage, and thirdly, when the PKM activity ends, the farmers were motivated to implement good cage management techniques, in order to increase their body weight and decrease mortality rate. The result showed that the pig farmer group was able to understand the recommended cage management process needed to achieve a standard body weight and a lower mortality rate from $30 \%$ to $15 \%$ such as the size, shape, type and cleanliness.
\end{abstract}

Keywords: Baru Village, Marga Sub-district, Cage Management, Mortality

\section{Pendahuluan}

Secara tofografi, Desa baru, Kecamatan Marga, Kabupaten Tabanan merupakan daerah landai dengan ketinggian: 500 - 700 meter diatas permukaan laut, curah hujan 4.500 mm/tahun. Berdasarkan surat Pimpinan DPRD Kabupaten Tabanan tanggal 11/2/2010 No 170/137/DPRD disetujuinya adanya pemekaran Desa yaitu Desa Tua menjadi Desa Induk dan Desa Baru ditetapkan menjadi Desa Persiapan, dan pada tanggal 22 Pebruari 2010 dengan menunjuk I Ketut Sudiarta menjadi Perbekel selanjutnya pada hari Rabu, 9 pebruari 2011 menjadilah Desa Definitif.

Adanya permasalahan dalam pencapaian bobot badan babi masih ada di bawah bobot standar sekitar $15 \%$ dan mengurangi mortalitas yang belum bisa ditangani oleh kelompok Mitra. Jumlah Babi di Kelompok Tani Ternak Sekar Nadi di Desa Baru berjumlah sekitar 102 ekor, dari jumlah tersebut yang belum mencapai bobot optimal yaitu $15 \%$, sedangkan untuk angka mortalitas masih diatas angka normal yaitu 11-24\% (Cameron, 1992, Becker,1999). Dari hasil survey di lapangan, angka mortalitas rata-rata pada peternak babi di Desa baru 
berkisar 30\% dari 55 ekor anak babi. Mitra kerja memohon kepada lembaga Fakultas Pertanian, Program Studi Peternakan, Universitas Warmadewa untuk memberikan penyuluhan dan pelatihan manajemen pemeliharaan dan manajemen kandang pada usaha ternak babi.

Solusi yang akan kami lakukan untuk mengatasi permasalahan tentang bobot badan yang rendah dan mortalitas yang masih tinggi adalah:

1. Kami akan mengadakan penyuluhan mengenai manajemen kandang pada pemeliharaan ternak babi.

2. Kami akan terjun langsung ke lapangan untuk memberikan penyuluhan mengenai manajemen kandang sampai anggota kelompok mengaplikasikan/menerapkan metode yang kami berikan serta melakukan evaluasi beberapa kali, sampai masa panen dan melihat hasilnya.

3. Jika kegiatan PKM sudah berakhir kami akan menyumbangkan beberapa contoh desinfektan, vitamin dan alat untuk menunjang usaha tersebut.

Target dan luaran yang ingin dicapai atau yang akan dihasilkan sesuai dengan rencana kegiatan adalah:

1. Mitra mampu menerapkan manajemen pemeliharaan khususnya manajemen kandang dalam usaha ternak babi,

2. Mampu menghasilkan bobot babi yang sesuai atau lebih tinggi dari standar dan menurunkan angka mortalitas sehingga meningkatkan kesejahteraan anggota kelompok ternak babi. 


\section{Metode Pelaksanaan}

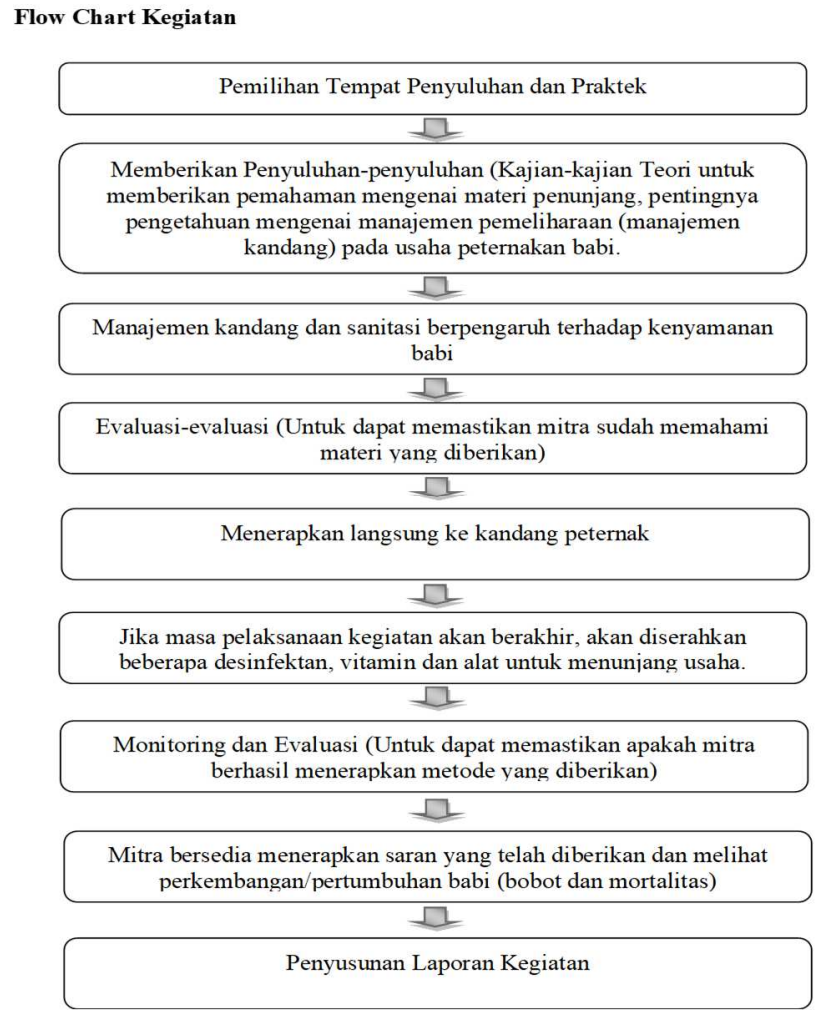

\section{Hasil Dan Pembahasan}

Kegiatan Program Kemitraan Masyarakat telah berjalan dengan lancar dimana masyarakat terutama kelompok Tani Ternak Sekar Nadi sudah melaksanakan sanitasi yaitu kesehatan, khususnya kesehatan ternak dengan melakukan kebersihan terhadap lingkungan perkandangan ternak babi di Desa Baru, Kecamatan Marga, Kabupaten Tabanan.

Tabel 1. Kegiatan dan luaran yang dihasilkan Kelompok Ternak Sekar Nadi

\begin{tabular}{llll}
\hline No & Kegiatan & Luaran & Keterangan \\
\hline 1 & $\begin{array}{l}\text { Penyuluhan tentang kebersihan } \\
\text { kandang yang dapat }\end{array}$ & $\begin{array}{l}\text { Materi penyuluhan berupa } \\
\text { buku dan brosur }\end{array}$ & $\begin{array}{l}\text { Kelompok ternak aktif } \\
\text { dalalm diskusi }\end{array}$ \\
$\begin{array}{l}\text { mempengaruhi produksi ternak } \\
\text { Penyuluhan tentang pembersihan } \\
\text { kandang menggunakan }\end{array}$ & $\begin{array}{l}\text { Produk desinfektan Agri } \\
\text { Quat }\end{array}$ & $\begin{array}{l}\text { Peternak sudah mengetahui } \\
\text { takaran desinfektan yang } \\
\text { harus dipakai }\end{array}$ \\
& $\begin{array}{l}\text { Memperbaiki saluran } \\
\text { pembuangan kandang }\end{array}$ & $\begin{array}{l}\text { Pemakaian selang dan } \\
\text { ember untuk pembersihan }\end{array}$ & $\begin{array}{l}\text { Peternak sudah } \\
\text { memperbaiki saluran }\end{array}$ \\
\hline
\end{tabular}




\begin{tabular}{llll}
\hline & & saluran kandang & pembuangan limbah ternak \\
Kengaplikasian penggunaan & Produk desinfektan Agri & Kelompok peternak sudah \\
desinfektan & Quat & melakukannya \\
5 & Mengadakan evaluasi & Masyarakat mampu & Penurunan mortalitas anak \\
& meningkatkan & babi dari $30 \%$ menjadi \\
& meningkatkan kebersihan & $15 \%$, dan menurunnya \\
& & presentase bobot badan \\
& & babi yang belum mencapai \\
& & standar dari $15 \%$ menjadi \\
& & $10 \%$ \\
\hline
\end{tabular}

\section{Kesimpulan Dan Saran}

Dari pengamatan dan observasi langsung yang kami lakukan di lapangan bahwa:

1. Kandang pemeliharaan ternak babi setelah dilakukan penyuluhan syarat kandang yang baik seperti ukuran, bentuk, jenis dan kebersihan kandang.

2. Telah terjadi penurunan mortalitas anak babi dari $30 \%$ menjadi $15 \%$.

3. Menurunnya persentase bobot badan babi yang belum mencapai standar dari $15 \%$ menjadi $10 \%$

Diharapkan kepada peternak babi di Desa Baru, setelah PKM ini selesai dilakukan ada perubahan mengenai manajemen pemeliharaan ke arah yang lebih baik dan selanjutnya agar dipertahankan bahkan ditingkatkan

\section{References}

[1] Ardana,IB, dan D.K.H.Putra.2008.Ternak Babi Manajemene Reproduksi, Produksi dan Penyakit.Denpasar Udayana Univerity Press.

[2] Ariana, I. N. 2011. Pengaruh model lantai kandang dan jenis kelamin terhadap penampilan produksi anak babi lepas sapih. Majalah Ilmiah Peternakan, 14(1).

[3] Becker, N. 1999. Antibitic in Pig Farming. Pig International Vol.II.Juni 1999.

[4] Cameron,R,D.A.1992. Notes on Pig Management and Nutrition Departement Farm Medicine and Production Faculty Veterinary Science, Universitas of Quennsland, Australia.

[5] Setyaningrum. 2003. Manajemen Ternak Potong. Unsoed. Purwokerto

[6] Sihombing, D.T.H.1997. Ilmu Ternak Babi. Fakultas Peternakan IPB Bogor 